\title{
The Impact of Technology in Public Sectors Workers' Performances in Nigeria: Case of Federal Ministry MDAs and Agencies
}

\author{
Article by Fred-Osogu Obioma \\ Ph.D, in Management, Texila American University, Guyana \\ E-mail: fredobioma@yahoo.com
}

\begin{abstract}
This paper provides information about the worker's productivity and performances in Nigerian public service operations. It clearly outlines the productivity and performances decrease that faces employees inside of workplace of Nigerian public sector. The article further argues that the deficiency in the perfect usage of technology, computer systems and communication networks (internet) is lack of interest of the organization to prepare a training schedule. It is the failures of respective Ministries and Agencies (Heads of Affairs) to train the staff on the use of technology in work place. These factors are among others which effect on the productivity and performances causing the employees to be less productive at their workplaces. Consequently, this has the negative effect on the economy. In addition, the decrease of individual productivity and performances is evidenced via the outcome of the survey of individuals who has shortage of interest of the management to prepare a time training schedule and system of computing to work within the country of Nigeria. Therefore, the paper recommends measures which should be taken to improve productivity and performances of workers by training them on Computer technology. The training can be inside or outside in the organization, which could lead to improvement in the input loutput performances of individual work staff, all workforce and economic development of Nigeria in general.
\end{abstract}

Keywords: Technology; Training; Computing System; Internet; Workers Performances \& Productivity.

\section{Introduction}

Over the past many decades there are dramatic changes within the forms of technologies offered to businesses whether public or private. The speedy development and diffusion of recent data technologies such as computers, communications and networks has altered the production process in several workplaces. In conjunction with these basic changes in the physical capital of firms or organizations, it is jointly and widely believed that the introduction of those new technologies has altered the structure of employment [Mark D, Timothy D, Kenneth T \{1997\}]. Productivity has increased in workplaces where computer usage is applied. This is unlike most of the ministries and agencies in Nigeria. Employers and policymakers have emphasized the importance of talent and skills upgrading of employees and long learning so as to deal with accrued pressures elicited by technological modification and economic process (Example European Commission, 2007).

There exists an oversized literature showing that the accumulation of human capital through the overall education system plays a vital role in explaining long financial gain but differences between wealthy and poor countries is also in modernization of operations with new developments in science and technology. Abundant less work exists on the application of training on computers. It usually brings specific skills from their employees to step up work preferences. In training on computer, it is important there is a distinction between identity, firm or organization's specifics and general training for the purpose of the required job and its output. General training ends up in skills that are equally applicable to alternative corporations whereas skills acquired through firm-specifics coaching area unit lost once the skilled worker leaves the firm or organization that provided coaching. By excellent competition within the market, employees ought to get hold of prices of general training and recoup these prices by earning higher wages. Once training is particularized, firm pay (part of) the training costs. However, in varied cases companies offer and get hold of training which is general in nature. They show how it could be explained by labour market imperfections. Particularly, a necessary condition for organizations to get hold of general training is that wages increase less steeply in training than productivity. This can 
be stated as a compressed wage structure which may be caused by frictions within the market like search prices, informational asymmetries, potency wages and labor markets establishments inform of unions or the presence of earnings laws. With a compressed wage structure, training will increase the marginal product of labour over wages that creates incentives for the firm to take a position in training. Like the instances above, in recent years that computer power itself has enabled researchers to statistically interrogate large scale datasets on firms, organizations and providing some more solutions to the issues of large volume storage and retrieval [John V, Reenen RS (2005].

The importance of skill upgrading of workers and lifelong learning in order to cope with increased pressures induced by technological change and globalization would amount to nothing if the computer knowledge could not be applied in the operations (European Commission, 2007). However, while there are researched literatures showing that the accumulation of human capital through the general education system that plays a crucial role in explaining long run income differences between rich and poor countries. Much less work exists on the effects of training provided by firms, often requiring and based on specific skills from their workers [Konings J Vanormelingen S (2010].

\section{The scope and structure of this study}

This study is structured as follows: 1. a brief review of the main trends in the empirical literature used in the analysis of the impact of technologies (computing and communications) on productivity or performance, 2. The important of training employees on the use of computer technology in workplace for productivity and performance increase. 3. Reports and discusses on the results of the statistical analysis. 4, the last section concludes, highlighting the main implications of our results findings. Finally, 5 concludes and recommends.

\section{Review of relevant literature}

The works of research studies carried out in US by Kristen and Lee, [2014]; they have validated the fact that workers on their productivity are affected by the Internet. They reported that the six in ten approximately $61 \%$ of American workers who strongly agree on use of the internet say email is "very important" for doing their job, and 54\% agreed say it is important (the same about) the internet. Far fewer workers describe landline phones (35\%) or cell phones and smartphones (24\%) as "very important." Just 4\% say social networking sites like Twitter, Facebook or LinkedIn are "very important" to their work. According to Kimmo [2012] to increase productivity, the employer should have up-todate internal communication guidelines and organize training and other support for employees, particularly when new communication tools are taken into use. More than that, including sharing, archiving relevant information and documents also should be available for co-employees as a common practice. Additionally, to evaluate the degree of workers' skills and recording the output at work, it is possible to estimate the impact of the training on productivity and performances at the workplace. This therefore led to the question why computer training for employees which Cecile Peterkin (2017), Milton Kazameyer (2007) and Bill Gates, the founder of Microsoft answered. Their detailed responses are stated here under.

\section{Why computer training for employees is highly recommended}

2017 Cecile Peterkin a computer training specialist stated that training employees in computer skills is essential in the workplace. The importance can be viewed in two ways. Basically, job applicants need to have computer training in order for them to become more valuable to their potential employers, and also to enable them to find jobs that pay well. Secondly, companies need to include computer training in their training program for new employees. When everyone at work is proficient in using computers, the company is likely to benefit from high employee productivity and efficiency. Explaining further, Cecile Peterkin stressed the importance as follows;

\section{Important job skill}

Computer skills are an important requirement for many types of jobs. As a job seeker, you will realize that in almost all office jobs out there, applicants are required and even expected to have excellent computer skills. You need to have at least basic data entry or typing skills. You should also have a good understanding of how an operating system is used. 
Most of the tasks in the office also require employees to have familiarity with some important and useful software and programs, too. And even in some non-office jobs, a bit of computer knowledge and training is required. In short, computer skill is essential. If you don't lack such skills, you will succeed in your job search and high performances productivity on the assigned jobs.

\section{Training on the job}

Basic training on how to use computers provides a strong foundation which workers can develop new skills on. In most cases, companies offer such training to their new employees. For instance, newly hired workers need to know how a proprietary software program is used. Managers can't expect new personnel to know how to use their specific software or programs. Thus, the organization has to invest in the training of their workers, especially the newcomers.

\section{Increased productivity}

As mentioned earlier, basic computer training is a way for companies and businesses to increase their employees' productivity. Employee training can also be conducted on computers. This will help streamline the entire training process, thus allowing the company to save on time and money.

\section{Employee development}

Basic computer training will obviously help employees develop skills that they need to be effective in their jobs. But aside from the technical skills that can be enhanced through computer training, the more important benefit of computer training is in the way it boosts employees' confidence. Personal development is a very important factor that can lead to worker satisfaction and increased productivity. When employees feel that they are learning something from their job, they are likely to stay and stick with the company.

Providing basic computer training is highly recommended by business administrators' and experts. Business consultants would always advise managers and company owners to invest in employee training, such as computer training, because at the end of the day, it is the business or the organization that benefits from the skills of its workers.

\section{The organizational concepts of productivity and performances}

Productivity and performance characterize the efficiency of productive output of workers, which is expressed by the number of products or services par unit time. Performance is the value of functional abilities of the body characterized by the quantity and quality of work at maximum intensity or activity. The type of performance and frequency of its changes are related to the duration of human and her Functional State (FS) phases outlined works [Doroshev VG; 1988] and Gavrilov et al. [2008].

According to Rohan and Madhumita [2012] companies, today are forced to function in a world full of change and under various complications and competitions. It is more important than ever to have the correct employees at the correct job with the right qualification and experience in order to survive the surrounding competition.

The successful and prosperous future of an organization is dependent on its skilled, knowledgeable and well-experienced workforce that is why training is a fundamental and effectual instrument in the successful accomplishment of the organizational mission, vision, goals and objectives. Training not only improves them resourcefully, but also gives them a chance to learn their job virtually and perform it more competently thereby hence service delivering, increasing firm's productivity and performance. Training has been an important variable in increasing organizational productivity, according to the Researchers' comments like Colombo and Stanca [2008], Sepulveda [2005], Konings and Vanormelingen [2009].

\section{The importance of computer in business organization}

Computers have become such an integral part of our lives because we rely on them for numerical calculations, storage of data, communication, and technological processes. Computers are simply complex counting devices. The abacus was an ancient computer which used beads to solve mathematical problems. Business software or a business application is any software or set of computer programs used by business users to perform various business functions. These business applications are 
DOI: $10.21522 /$ TIJAR.2014.06.01.Art004

ISSN: $2520-3088$

used to increase productivity, to measure productivity and to perform other business functions accurately.

By and large, business software is likely to be developed to meet the needs of a specific business, and therefore is not easily transferable to a different business environment, unless its nature and operation is identical. Due to the unique requirements of each business, off-the-shelf software is unlikely to completely address a company's needs. However, where an on-the-shelf solution is necessary, due to time or monetary considerations, some level of customization is likely to be required. Exceptions do exist, depending on the business in question, and thorough research is always required before committing to be spoke or off-the-shelf solutions.

Some business applications are interactive, i.e., they have a graphical user interface or user interface and users can query/modify/input data and view results instantaneously. They can also run reports instantaneously. Some business applications run in batch mode: they are set up to run based on a predetermined event/time and a business user does not need to initiate them or monitor them. Some business applications are built in-house and some are bought from vendors (off the shelf software products). These business applications are installed on either desktops or big servers. Many kinds of users are found within the business environment, and can be categorized by using a small, medium and large matrix: Wikipedia, the free encyclopedia, 2017 stated as follows:

- The small business market generally consists of home accounting software, and office suites such as OpenOffice.org or Microsoft Office.

- The medium size, or small and medium-sized enterprise (SME), has a broader range of software applications, ranging from accounting, groupware, customer relationship management, human resource management systems, outsourcing relationship management, loan origination software, shopping cart software, field service software, and other productivity enhancing applications.

- The last segment covers enterprise level software applications, such as those in the fields of enterprise resource planning, enterprise content management $(\mathrm{ECM})$, business process management (BPM) and product lifecycle management. These applications are extensive in scope, and often come with modules that either add native functions, or incorporate the functionality of third-party computer programs.

They are to be studied and applied in the daily job's executions for better productivity and performances. The importance of computer in business lays in the roles it plays in speed up the business processes and systems with top quality. Today's world computer is important to use to start any online and offline business. A computer is important to use in business to automate the manufacturing, marketing and, distribution process among others. Business software or a business application is any software or set of computer programs used by business users to perform various business functions. These business applications are used to increase productivity, to measure productivity and to perform other business functions accurately.

In organization, computers allow the application of different types of software that can help businesses keep track of their files, documents, schedules and deadlines. Computers also allow businesses to organize all of their information in a very accessible manner.

A broad term for a commercial entity involved in the computer industry. Examples of computer businesses include hardware and software manufacturers and retailers, software developers, PC repair and service companies, computer training, firms, computer networking businesses, computer consultants and more.

Computers have both advantages and disadvantages. On one hand, they allow us to access the wealth of information that is available on the internet. They also allow us to analyze massive amounts of data very quickly, saving both time and money.

\section{Importance of computers in the general business world}

The world is in an age of booming technology, running a business without computers is breathing without lungs. Take it or leave it, technology has become an integral part of the way business is done. Even when performing business services or providing products which are not technology related, to be getting your raw materials, computer network is need to place orders. Today we have mega shops dealing virtually I all materials. Such businesses like; dry cleaning, hairstyling, multiple article retail, 
wholesale, distribution shops and among others, one may find that without a computer, it's difficult to place orders with suppliers or pass information to target market dealers or customers.

\section{Inventory management}

Inventory Management Retail and wholesale business have increasingly come to rely on computers' advanced ability to keep track of inventory and assist in ordering more when stocks get low. In fact, one of the central approaches to the success of retail giant like WalMart, shoprite just to mention two, was real time ordering in which WalMart's computer systems place orders for goods as they are needed. This allowed them not to carry too much or too little of any particular item as well as to save on the manpower required to manage much of the supply chain. However, businesses of all sizes use inventory management and point of sales systems to do smaller scale versions of the same thing. Presentations and Documents While it's still possible to find a typewriter at a garage sale, the days of typed papers and documents are dead and gone.

\section{Word processing}

Word processing is a must in today's business environment. Not only are computers the medium for document creation, but the ability to email and share documents electronically has become central to the editing, approval and delivery process. Similarly, presentations and reports are commonly delivered in electronic slide show presentations or via webinars. Creators must use programs, such as PowerPoint, to create them as this is the standard for modern business.

\section{Electronic communications}

Electronic Communications has become information channels of feedback mode. A business not involved in electronic communications like use of email shall be in obsolete corner now. E-mail is one of the largest communication channels today. Customers, clients, vendors and business partners use email to make contact and transact business. Some companies go beyond email and actually encourage the use of in-house instant messaging as a method of communications between employees and departments.

\section{Internet accessibility}

Access to Internet is a business' communications lifeline. Internet-enabled computing to allows one to receive orders from customers, place orders with suppliers, research businesses, explore business ideas, communicate with government agencies and even manage your business' banking. In addition, online presence with at least a website is critical to legitimizing a business. Many companies go further and participate in social networking sites for marketing and branding purposes. Multi-site Networks If a business has more than one site or branch, then multi-site networking provides tremendous benefits for accounting, standardizing and managing your multi-faceted operation. Many companies use point of sale systems to ensure standardized operations within a chain of stores or sites. Companies that sell similar products or services in multiple locations find that computer systems help them keep track of revenues, costs and their supply chain from a central office. This allows a centralized management team to get reports on any or all sites and get a macro-view of the business when needed.

\section{Why computer-based training (CBT) in organization}

The general view is that computer-based training allows trainees to work at their own learning pace and style, both of which can be adjusted to match the individual needs of each trainee. Computer-based training is non-threatening and non-judgmental while providing immediate feedback as the training progresses.

This is a skill needed in almost every workplace. Education and the necessary experience are important for any successful career. But gaining computer skills, on the other hand, will help improve overall knowledge and understanding of the tasks, job performances and total productivity. 
DOI: $10.21522 /$ TIJAR.2014.06.01.Art004

ISSN: $2520-3088$

\section{Computer-based training (CBT)}

CBT is any course of instruction whose primary means of delivery is a computer. A CBT course is also sometimes called courseware. It may be delivered via a software product installed on a single computer, through a corporate or educational intranet, or over the Internet as Web-based training.

\section{Computer-based learning (CBL)}

Computer-based learning (CBL) is the term used for any kind of learning with the help of computers. Computer-based learning makes use of the interactive elements of the computer applications and software and the ability to present any type of media to the users. Computer skills are essential in order to utilize computers and related technology efficiently. After you've mastered the basics, this course will help one learn about Internet and email, computers, word processing, multimedia, and spreadsheets. The most common software currently being used for office work is word processing software like Microsoft Word, spreadsheet software like Microsoft Excel, and presentation software like Microsoft PowerPoint. It's important to refresh your skills with these basic programs.

\section{The importance of computer training in the workplace}

According to Milton Kazmeyer (2007) a writer and an expertise in computers, astronomy, alternative energy sources and the Environment, in the modern workplace, computer skills are an incredibly valuable addition to any employee's personal portfolio. As a worker, developing and cultivating computer skills can greatly increase your desirability to employers, and it can allow you to take on roles you might not have previously considered. As an employer, training your employees in computer skills can not only increase productivity but also help you stave off problems that can cost time and significant amounts of money to fix. Explaining further, the following salient points was added on why workforce must be trained in computer usage.

\section{Computer skills}

These days, it is hard to find a job that does not involve a computer in some way. PCs are ubiquitous in any office environment, and even blue-collar workers may enter data into terminals or use portable devices to look up information on the job. Even the most basic retail cashier positions often involve the use of a computerized point-of-sale system. Familiarity and experience with computers can benefit almost any type of worker.

\section{Training and experience}

Training in basic computer skills can greatly affect how quickly a new hire picks up the specific applications unique to your business. To someone without computer experience, a PC can be an unnerving, unfamiliar piece of hardware, and the constant fear of causing some catastrophic error can make it difficult to feel at home at the keyboard. Training new employees in computer skills will ensure that everyone has the basic knowledge they need to function at your business, and it can help new-hires with computer skills gain familiarity with your specific business systems.

\section{Productivity}

Studies have shown that computers increase productivity, but those gains can only be realized if employees are comfortable and experienced with the systems. According to the Information Technology and Innovation Foundation, investments in technology produce gains in productivity three to five times greater than other investments by allowing employees better access to the information they need to do their jobs. Ensuring that your employees are trained and familiar with computers will help them spend less time tracking down that information and more time utilizing it to perform vital tasks for your company.

\section{Computer safety}

Giving your employees some basic computer knowledge can also help you head off problems. Malware programs and hackers often rely on user error or ignorance of common traps to gain access to a system, and training your employees in how to avoid these mistakes can greatly enhance your 
business's online security. A simple training course in how to spot phishing attempts, in which a user or Web site employs deception to extract data from unwitting employees, may mean the difference between keeping your company's network secure and losing vital data to an outsider.

The advent of computers has revolutionized the workplace and redefined operational practices. The use and deployment of computers, computer systems and information technology (IT) applications in every aspect of business is now commonplace. The recent application and adoption of Web-based, information and telecommunication technologies have force-multiplied the capabilities and benefits of computers. The importance of computers in business cannot be overstated.

Businesses are using Internet communication technologies, networking and relevant software to enable workers and professionals to collaborate and work across locations and geographical boundaries and streamline work-flow management.

Computer systems connected over a Web-based environment or an intranet-based network can communicate with each other. Varied connectivity and access technologies with computing interfaces facilitate communication of employees with business partners, suppliers, customers, government regulators and other stakeholders.

Deployment of Enterprise Resource Planning (ERP) software solutions, Management Information Systems (MIS), other information management and business intelligence technologies help businesses to centralize core business activities and operations, manage gigabytes of generated information and aid decision-making processes.

Software, productivity tools and networking applications installed in computers, laptops and workstations enable employees in a business to streamline their work-flows, execute assigned tasks faster and aim to achieve organizational goals and targets.

All businesses investing in computers and IT systems look to leverage the Return on Investment (ROI) parameter. Long-term planning and allocation of resources for IT are helping organizations to take up ambitious business expansion activities, channelize workforce productivity, adjust strategic goals and thereby positively impact the bottom line.

The employees cannot achieve these business operations in the workplace without the knowledge of computer and to apply it in their day to day job functions if they are not trained on the use of computer. Poor knowledge of computer has rendered public service work useless.

\section{Advantages of being computer literate in the workforce}

In the words of Bill Gates, founder of Microsoft, the internet is becoming the town square for the global village of tomorrow. We live in a world filled with technology. Just ten years ago, we didn't encounter as many computers as we now do. The reality is that we can't afford to be technophobes anymore. Computer literacy is not just a skill that's reserved for the elite set. It is time to embrace the technological revolution and equip ourselves for a bigger and brighter future. Bill gates said that: Just in case you've been living under a rock, the World Wide Web (WWW) has been alive and kicking for the last 25 years. The origin of the internet takes us back 45 years or so. This is the time of the digital and computer revolution.

With the help of the internet, we get to connect and communicate with people across the world. The internet has made it easy for people of different backgrounds to come together for business and social purposes in a way we would have never anticipated before. What has this got to do with computer literacy? Everything!

Basic computer knowledge allows us to 'browse' or 'surf the internet'. However, that is not all. With computer literacy and the internet, we have greater access to:

- Information and knowledge

- A greater understanding of culture and people of diverse backgrounds

- More information on emerging trends

- Greater connection to people from around the world on a social and business level.

For the past decades, the business operations are not possible without computers, and computers are a product of business. Computer technology is very important especially in the business field. It can help to make work easier. Computer is a powerful tool, allowing you easily extract data in order to 
DOI: $10.21522 /$ TIJAR.2014.06.01.Art004

ISSN: $2520-3088$

prepare reports and analyze the information. Computers can help a business stay in contact with its customers as well.

Computers can help managers keep track of the financial status of the company on a yearly, monthly or even day-to-day basis. Companies can use their computers to print checks for payroll and expenditures, and can form a direct link to the company's bank account. Computers through internet connection made business transactions easier and more convenient. As compared to hard copied data which is more prone to damage data saved in the computer is more secured. Thus, computer plays a big role and importance in the business field.

According to Pallab Dutta (2017), the advent of computers has revolutionized the workplace and redefined operational practices. The use and deployment of computers, computer systems and information technology (IT) applications in every aspect of business is now commonplace. The recent application and adoption of Web-based, information and telecommunication technologies have forcemultiplied the capabilities and benefits of computers. The importance of computers in business cannot be overstated.

Businesses are using Internet communication technologies, networking and relevant software to enable workers and professionals to collaborate and work across locations and geographical boundaries and streamline work-flow management.

Computer systems connected over a Web-based environment or an intranet-based network can communicate with each other. Varied connectivity and access technologies with computing interfaces facilitate communication of employees with business partners, suppliers, customers, government regulators and other stakeholders.

Deployment of Enterprise Resource Planning (ERP) software solutions, Management Information Systems (MIS), other information management and business intelligence technologies help businesses to centralize core business activities and operations, manage gigabytes of generated information and aid decision-making processes.

Software, productivity tools and networking applications installed in computers, laptops and workstations enable employees in a business to streamline their work-flows, execute assigned tasks faster and aim to achieve organizational goals and targets.

All businesses investing in computers and IT systems look to leverage the Return on Investment (ROI) parameter. Long-term planning and allocation of resources for IT are helping organizations to take up ambitious business expansion activities, channelize workforce productivity, adjust strategic goals and thereby positively impact the bottom line.

All these assertions point out that employees have to excel in the use of computer to work in their respective schedules of duties. Therefore, they have to be trained and be informed on the computer application technology in order to perform in boosting productivity.

\section{Why is it important to be computer literate in modern times?}

By the words of Bill Gates, the founder of Microsoft, the following salient points are also noted and identified in our world today business operations corning the computer knowledge: 


\section{Why Learn to Use a Computer?}

- To open up a world of information

- To easily access government \& other organizations

- To connect with family \& friends

- To have fun!

\section{This is the age of the personal computer revolution}

In answer to the why learn to use of computer, Bill gates said: "I think it's fair to say that personal computers have become the most empowering tool we've ever created. They're tools of communication, they're tools of creativity, and they can be shaped by their user."- Bill Gates

There is a new language emerging. Words such as coding, HTML and web design may have us approaching this world with a mixture of dread and fascination. The reality is that the children we bring into the world today will be the digital natives and influencers of tomorrow.

\section{The advantages of computer literacy}

In light of the above the following nine (9) reasons of being company literate in the workforce was identified.

\section{Computer literacy addresses the gap in your knowledge}

If you are a professional in your 30's or 40's doing the same thing on a daily basis, you probably know that you need a little technological push in the right direction to reach your full potential. Many people unwittingly settle in their careers for fewer chances and opportunities because they feel as if, 'you can't teach an old dog new tricks'

What a sad loss of rich intellectual heritage and experience!

With a little training in basic computer skills you could be flying in your career! Digital skills training has a way of opening doors and directing dreams. You can easily sign up and study part-time so that you can bridge the gap in your understanding.

The world is moving toward digital education faster than the blink of an eye. If you want to get ahead it pays to adopt the mind-set of the new digital natives.

\section{Computer Literacy supports Entrepreneurship}

With a whole new world that is literally at your fingertips, doesn't the prospect of your own development get your pulses racing? Being computer literate will open your world up to new ideas, enable your self-confidence and help you to innovate. Just imagine all you need is an internet connection, a PC or laptop and a little bit of business sense and you could be streets ahead. Now more than ever tech skills for entrepreneurs are of great importance. 
DOI: $10.21522 /$ TIJAR.2014.06.01.Art004

ISSN: $2520-3088$

\section{Depolarization of the office space - a new and real phenomenon}

With the increased digitization of the world and the processes that we engage in, even our offices have become virtual/digital spaces. Depending on your industry and if you have the option to do so, you could easily work from home, a holiday destination, the beach or anywhere else that you choose.

\section{Computer literacy skills command innovation}

As you get savvier with your computer skills, you will be inspired to innovate, experiment, try new things and get ahead in your industry with the New apps, new coding programs, blogging, you name it. The digital world is yours for the taking and working with.

\section{The importance of computer literacy in education}

There are different markers of development along the education journey. Assuming a child receives early exposure to computer skills training, one of the end-goals as that child matures is to be computer literate.

\section{Helps students to navigate digital learning platforms}

Students stand to benefit from their early computer literacy skills training as it will help them to navigate digital learning platforms. Many colleges and institutions of higher learning make use of elearning courses. At this phase computer literacy helps immensely in allowing the student to navigate the technology needed to engage with online learning platforms.

\section{Enhances job opportunities}

Before a student enters the working world, it is imperative that they receive some kind of computer skills training. Computer literacy prepares students for the norms and algorithms of the business world. Having some level of computer literacy enhances job opportunities. You can easily study a Short Programme in Fundamentals of Microsoft Office to help you on your way.

\section{Communication}

It goes without saying that the business world involves a great deal of communication. This is both interpersonally and electronically. Think emails, presentations, workshops, Skype calls and so on. There is always a level of computer literacy involved.

\section{Computers streamline business processes}

Previously, business processes used to be very tedious. Before we really, truly embraced computer skills one might have sent a staff member around the office to get people to sign a memo. Nowadays an email or giving somebody your banking details in which to deposit funds is just as good as being there or sending somebody to the bank.

Embrace the fact, computers are here to stay! Instead of computers being the kind of equipment that stands between us and our personal success, we should embrace the convenience and the revolution that they bring to our worlds. Computer literacy is the new currency that will help pave your path to your career and personal development. Therefore, it is time to bring you up-to-date in computer technology application appliance in business and individual life.

\section{Research methodology}

The statistical methods used in this study are obtained by survey and questionnaires. Due to the advantages presented by the data analysis, these approaches are adopted to analyze the statistical data by the survey method was used for data. The information related to technology and workers' productivity was collected through interviews and survey. These interviews were carried out based on the personal opinions of high rank heads of Department MDAs/ agencies and questionnaires with statistical data analysis. The survey included 50 from 200 employees working in different Nigerian ministries and agencies sampled randomly. While the real return of questionnaires form was 37 from 50 applications were applied on employees in this survey. 
The attitudinal questions attempted to reveal the viewpoints, opinions, and the perceptions of the interviewees with respect to the different dimensions and variables of the technology, communication, training, and productivity by using the Likert scale has been utilized to measure the study sample. In order to derive a usable questionnaire for this research, many standard questionnaires regarding technology, performance and productivity were investigated.

Furthermore, the reliability of the questionnaire in these studies has been assessed by Cronbach's alpha as percent (0.946), which is an appropriate criterion for evaluating the reliability of the measurement tools. Through a pre-test done by using the IDM / SPSS package and Cronbach test.

Table 1 and 2 below illustrates how the total reliability of the questionnaire was determined

Table 1. Case processing summary

\begin{tabular}{|l|l|l|}
\hline & Number & $\mathbf{\%}$ \\
\hline Valid & 37 & 100 \\
\hline Excluded & 0 & 0 \\
\hline Total & 37 & 100 \\
\hline
\end{tabular}

Cases

Table 2. Reliability statistics

\begin{tabular}{|l|l|}
\hline $\begin{array}{l}\text { Cronbach's } \\
\text { Alpha }\end{array}$ & $\begin{array}{l}\text { No. of } \\
\text { Items }\end{array}$ \\
\hline 0.946 & 35 \\
\hline
\end{tabular}

Note $=35$

$=0.946$

\section{Discussion of tables, data analysis and results of findings}

This study examined the relationship between technology and workers 'performances and productivity in Nigeria ministry and agency. The empirical data collected is based on the perceptions and opinions of civil service employees. Data analysis was used to test via a statistical program which is SPSS. Results of this case study of Ministries and Agencies workers in Nigeria indicated that a positive relationship exists between technology, performances and productivity.

\section{Technology, performances and productivity}

The analysis provided strong supporting for the relevance of the technology on productivity / performances. Moreover, there is a correlative relationship between technological changes in productivity and performances of the individual. The more of administration and policy makers is interested in keeping up with the modern and advanced technological changes to production of goods and services, the more to achieve more in productivity and performances of workers. The findings of this study indicated that the perceived usefulness of technology has a significantly positive influence on employee's productivity and performances.

In summary, results of the data analysis for our research are as shown below Tables. As a result, in this section, it can be shown the correlation between technology and individual's productivity and performances in terms of the percent of workers answers is around 90\% which says their ministry or agency encouragement of employees training is important to make modern use of technology to boost productivity and performances in service delivery. 
DOI: $10.21522 /$ TIJAR.2014.06.01.Art004

ISSN: $2520-3088$

Valid

Table 2. Management recognizes the importance of technology in the productivity and performance

\begin{tabular}{|l|l|l|l|l|}
\hline $\begin{array}{l}\text { Degree of } \\
\text { Opinion }\end{array}$ & Frequency & Percent & Valid Percent & Cumulative Percent \\
\hline Disagree & 2 & 5.4 & 5.4 & 5.4 \\
\hline Neutral & 2 & 5.4 & 5.4 & 10.8 \\
\hline Agree & 21 & 56.8 & 56.8 & 67.6 \\
\hline $\begin{array}{l}\text { Strongly } \\
\text { Agree }\end{array}$ & 12 & 32.4 & 32.4 & 100.0 \\
\hline Total & 37 & 100.0 & 100.0 & \\
\hline
\end{tabular}

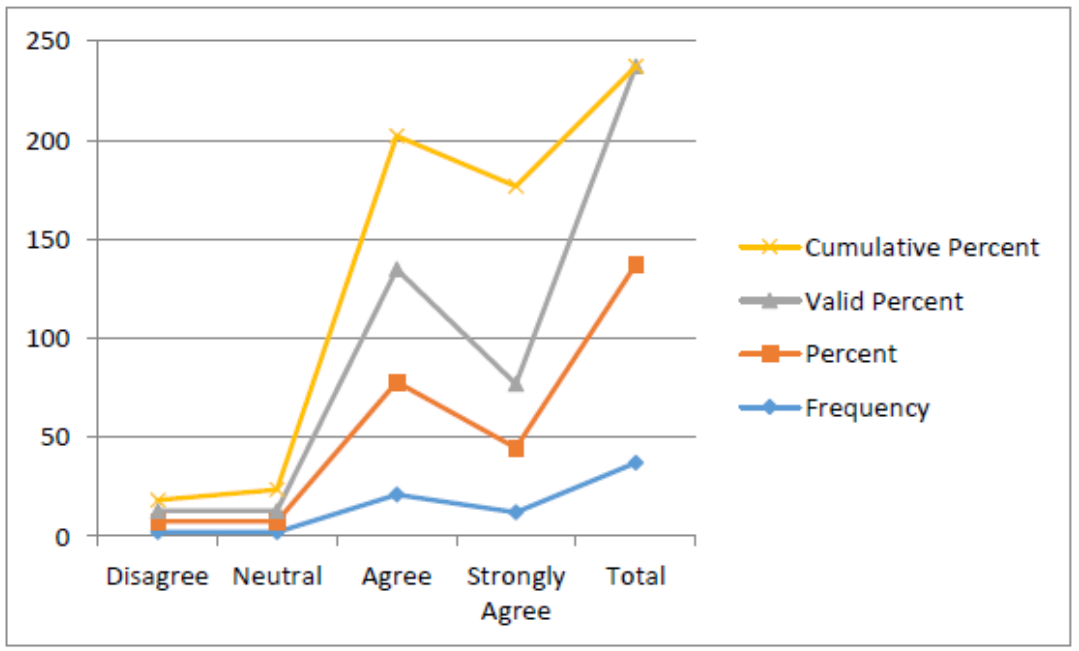

\section{Collecting information}

The workers' outcome management based to retain all data and information about customers by technological services. It has reduced by the employee's survey that the prevalent situation in the ministries and agencies which most of its workers are affected by technology and help them to increased performance. Therefore, the ministry / agency might keep whole documents about customers, $72.2 \%$ from employees have extremely strongly agreed about their ministry / agency should keep all documents for customers in computerized system. It leads to giving an extremely positive impact on the ministries/ agencies and its customers as it shows in Table $\mathbf{3}$ below.

Valid

Table 3. The ministry / agency management based to retain all data and information about Customer by Technological Service (computerize system)

\begin{tabular}{|l|l|l|l|l|}
\hline Degree of Opinion & Frequency & Percent & Valid Percent & Cumulative Percent \\
\hline Disagree & 2 & 5.4 & 5.4 & 5.4 \\
\hline Neutral & 2 & 5.4 & 5.4 & 10.8 \\
\hline Agree & 21 & 56.8 & 56.8 & 67.6 \\
\hline Strongly Agree & 12 & 32.4 & 32.4 & 100.0 \\
\hline Total & 37 & 100.0 & 100.0 & \\
\hline
\end{tabular}

\section{Internet and marketing}

The ministry / agency management has not much adopted the use of the internet in the service delivery processes of the products and services to reduce production costs and increase customer satisfaction. This indicates a lack of optimal using of technology. While the existing old technology: customer archive and a computerization system in the ministry / agency are obsolete. The overall of 
this variable have negative impact on productivity and performance. This shows that technology is not applied in the best and up to date way. This is evident from the responses of the respondents, where the percentage of use of technology in the public office for the Internet was about $48.6 \%$. This effect is not positive for management, taking into account that the presence of technology, its uses in goods and services, delivery and production processes through the internet which is clearer and faster in modern services of customers.

This is shown in Table 4 below.

\section{Valid}

Table 4. The ministry / agency management adopted the use of the Internet in the service delivery processes of the services to reduce production costs and increase customer satisfaction

\begin{tabular}{|l|l|l|l|l|}
\hline Degree of Opinion & Frequency & Percent & Valid Percent & Cumulative Percent \\
\hline Strongly Disagree & 3 & 8.1 & 8.1 & 8.1 \\
\hline Disagree & 9 & 24.3 & 24.3 & 32.4 \\
\hline Neutral & 7 & 18.9 & 18.9 & 51.4 \\
\hline Agree & 10 & 27.0 & 27.0 & 78.4 \\
\hline Strongly Agree & 8 & 21.6 & 21.6 & 100.0 \\
\hline Total & 37 & 100.0 & 100.0 & \\
\hline
\end{tabular}

The table was further put to Line graph to show levels in percentage.

\section{Below is the line graph}

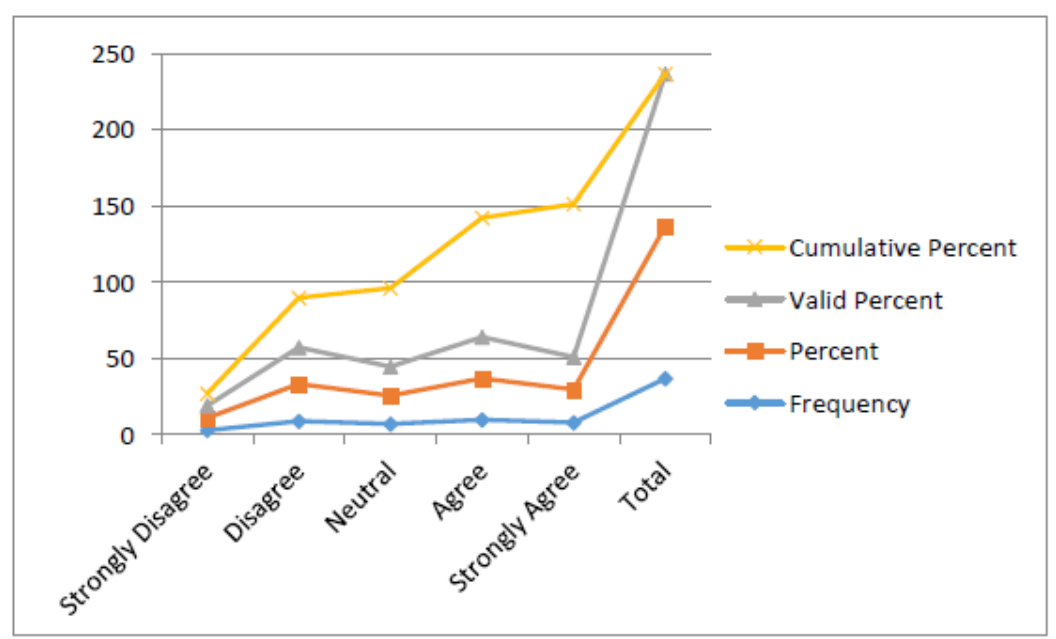

\section{Employees training}

This final section presents the statistics analysis of workers training on use of modern technology by developing a time schedule to improve performances and production. It can be noted that the percent of research sample was $29.7 \%$ as demonstrate Table 5, who wish the management does not base to work on employees training. In other words, the workers do not get on the job computer training. On the words, the workers 'do not get on perfectly skills schedule processing on modern technology in the ministry or agency as required and discussed above. It therefore stands to conclude that there appears a substantially large impact of training on productivity. The achievement and performances of workforce is poor and ends in obscurity generally. 
DOI: 10.21522/TIJAR.2014.06.01.Art004

ISSN: $2520-3088$

\section{Valid}

The Ministry / Agency management sees to the training of employees in us ing modern technology by developing a time schedule to improve production.

Table 5. Data Analysis

\begin{tabular}{|l|l|l|l|l|}
\hline Degree of Opinion & Frequency & Percent & $\begin{array}{l}\text { Valid } \\
\text { Percent }\end{array}$ & Cumulative Percent \\
\hline Strongly Disagree & 11 & 29.7 & 29.7 & 29.7 \\
\hline Disagree & 9 & 24.3 & 24.3 & 54.1 \\
\hline Neutral & 6 & 16.2 & 16.2 & 70.3 \\
\hline Agree & 10 & 27.0 & 27.0 & 97.3 \\
\hline Strongly Agree & 1 & 2.7 & 2.7 & 100.0 \\
\hline Total & 37 & 100.0 & 100.0 & \\
\hline
\end{tabular}

\section{Graph representation with line graph}

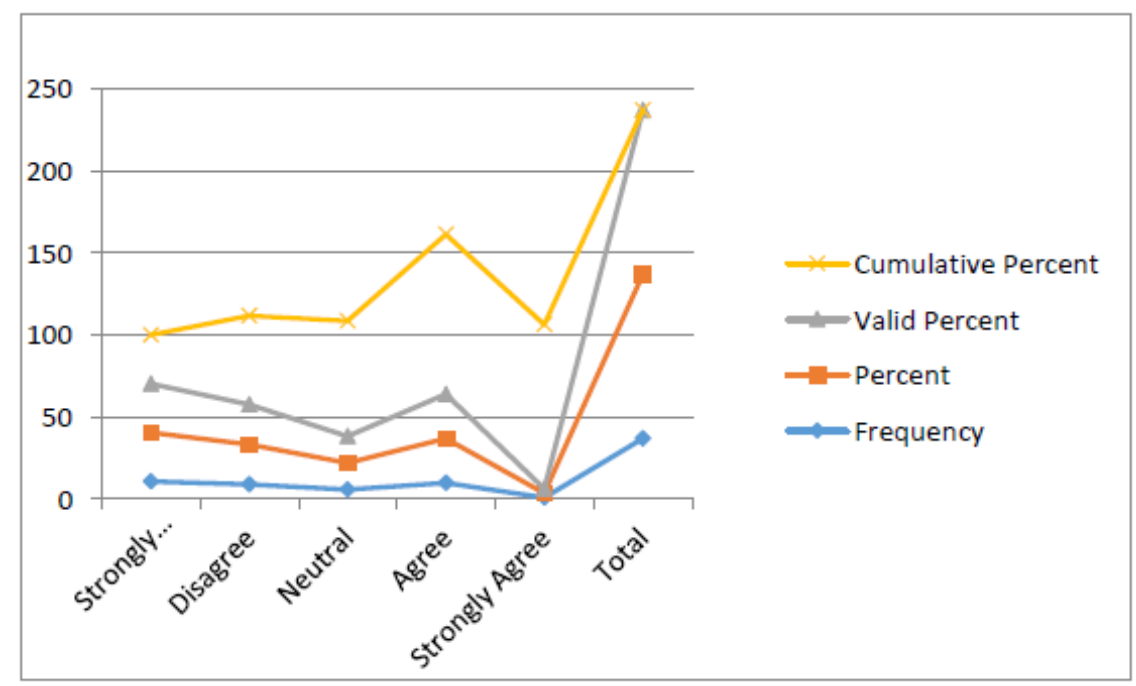

\section{Conclusion and recommendations}

It is important to understanding that the use technologies are basic in organizations for effective and efficient performances. In terms of operations and distributions in global productivity, the viable efficient goods and services delivery cannot be covered without computer. It boosts productivity, efficiency and increases performances. One can see the difference from the kinds of technologies used in the service delivery by or across the developed world.

Technological inventions should be used altogether for different purposes and workers should be trained to use them accordingly. To seek how productivity can be improved with the use of technologies one has to apply a holistic view to unify all variables specifically, such as communication, the internet, and training.

The study among others have illustrated that the bulk of the evidence from this study is that technology does have ability to improve and develop of individuals skills. It also significantly impacts on productivity and performances of organizations generally.

Furthermore, it can be concluded that the impact of technologies on workers' productivity and performance is not limited but large with a lot of goodies.

In most cases, employees don't have high skills in use technology due to they have lacked good training.

Additionally, when the employee doesn't have good skills due to lack of perfect training that is considered a big element which have negative effect on productivity and performances in the workplace. 
To increase productivity and performances, the administration and policy makers should have up-todate internal communication guidelines and organize pieces of training and other support for employees, particularly when there is advanced new technology.

The study has suggested that organizing training for the employees or workforce basic knowledge will go a long way to develop them, improve and increase productivity as well as gear up their performances in today's service delivery and economy development.

\section{References}

[1]. Andriessen, Daniel (2004). "Reconciling the rigor-relevance dilemma in intellectual capital research". The Learning Organization. 11 (4/5): 393-401. doi:10.1108/09696470410538288.

[2]. Alavi, Maryam; Leidner, Dorothy E. (2001). "Review: Knowledge Management and Knowledge Management Systems: Conceptual Foundations and Research Issues". MIS Quarterly. 25 (1): 107-136. doi:10.2307/3250961. JSTOR 3250961.

[3]. Bontis, Nick; Choo, Chun Wei (2002). The Strategic Management of Intellectual Capital and Organizational Knowledge. New York: Oxford University Press. ISBN 0-19-513866-X.

[4]. Colombo E, Stanca L (2008)The Impact of Training on Productivity: Evidence from a Large Panel of Firms 35: $1140-1150$.

[5]. Doroshev VG (1988) Physiological regulation at the workplace. Nauka Press, Leningrad.

[6]. Ferguson, J. (2005). "Bridging the gap between research and practice". Knowledge Management for Development Journal. 1 (3): 46-54.

[7]. Gavrilov EV, Dmitrichenko MF, Dolya VK (2008) Systemology in transport. Ergonomics. Znannya Press, Kiev.

[8]. Groth, Kristina. "Using social networks for knowledge management" (PDF). Royal Institute of Technology, Stockholm, Sweden. Retrieved 18 April 2013.

[9]. Hayes, M.; Walsham, G. (2003). "Knowledge sharing and ICTs: A relational perspective". In EasterbySmith, M.; Lyles, M.A. The Blackwell Handbook of Organizational Learning and Knowledge Management. Malden, MA: Blackwell. pp. 54-77. ISBN 978-0-631-22672-7.

[10]. John V, Reenen RS (2005) information technology and productivity. It ain't what you do it's the way that you do I.T.

[11]. Konings J Vanormelingen S (2010) The impact of training on productivity and wages: firm level evidence, IZA Discussion Papers, No. 4731.

[12]. Kristen P, Lee R. Pew Research Center (December 2014) Technology's Impact on Workers.

[13]. Kimmo P (2012) The impact of communication technologies on individual workers' productivity. $\mathrm{k} 77303$.

[14]. Konings J, Vanormelingen S (2009) The Impact of training on productivity and wages: Firm Level Evidence, Discussion. Paper No. 244.

[15]. Mark D, Timothy D, Kenneth T (1997) Workers, wages, and technology. Q J Econ 112: 253-290.

[16]. Milton Kazmeyer (2007). Expert Computers, Astronomy, Alternative Energy sources and the Environment.

[17]. Mariposa Leadership; Technology -- Is It Helping Communication in Your Workplace?; Aug 02, 2007

[18]. Maier, R. (2007). Knowledge Management Systems: Information and Communication Technologies for Knowledge Management (3rd edition). Berlin: Springer.

[19]. Nanjappa, Aloka; Grant, Michael M. (2003). "Constructing on constructivism: The role of technology" (PDF). Electronic Journal for the Integration of Technology in Education. 2 (1). Archived from the original (PDF) on 2008-12-17.

[20]. Nonaka, Ikujiro; Takeuchi, Hirotaka (1995). The knowledge creating company: how Japanese companies create the dynamics of innovation. New York: Oxford University Press. p. 284. ISBN 978-0-19-509269-1.

[21]. Nonaka, I.; von Krogh, G. \& Voelpel S. (2006). "Organizational knowledge creation theory: Evolutionary paths and future advances" (PDF). Organization Studies. 27 (8): 1179-1208. doi:10.1177/0170840606066312.

[22]. Nottingham Trent University; A Study of the Impact of Information Technology on Business; Julie Eatock et al.

[23]. BusinessWings.co.uk; The Importance of Backing up Data Files; Vickie Lamb.

[24]. Small Business Bible: Some Advantages and Disadvantages of Information Technology.

[25]. Rohan S, Madhumita M (2012) Impact of Training Practices on Employee Productivity: A Comparative Study 2: 87-92. 
DOI: $10.21522 /$ TIJAR.2014.06.01.Art004

ISSN: $2520-3088$

[26]. "Rhetorical Structure Theory Website". RST. Retrieved 19 April 2013.

[27]. Snowden, Dave (2002). "Complex Acts of Knowing - Paradox and Descriptive Self Awareness". Journal of Knowledge Management, Special Issue. 6 (2): 100-111. doi:10.1108/13673270210424639.

[28]. Sepulveda F (2005) Training and Productivity: Evidence for US Manufacturing Industries. Oxf Econ 62: 504-528.

[29]. Serenko, Alexander; Bontis, Nick (2004). "Meta-review of knowledge management and intellectual capital literature: citation impact and research productivity rankings" (PDF). Knowledge and Process Management. 11 (3): 185-198. doi:10.1002/kpm.203. Archived from the original (PDF) on 2007-09-26.

[30]. Wyssusek, Boris. "Knowledge Management - A Sociopragmatic Approach (2001)". CiteSeerX. Retrieved 18 April 2013.

[31]. U.N. Food and Agriculture Organization: Computers as Management Tools. 